\title{
ENSINO POR PROJETO: UMA ABORDAGEM DINÂMICA E LÚDICA EM TEMPOS DE ENSINO REMOTO
}

\section{DOI: 10.37702/2175-957X.COBENGE.2021.3738}

Victória da Silva Braga - victoriabraga@id.uff.br Universidade Federal Fluminense Avenida Professor João Brasil 150 24130-082 - Niterói - RJ

Fabiana Rodrigues Leta - fabianaleta@id.uff.br Universidade Federal Fluminense

R. Voluntários da Pátria 100

22270-010 - Rio de Janeiro - RJ

Resumo: Objetivando trazer reflexão sobre questões sociais e financeiras vivenciadas no contexto da pandemia do novo coronavírus, foi proposto aos alunos de Introdução à Engenharia Mecânica, disciplina do primeiro período da grade do curso de Engenharia Mecânica da Universidade Federal Fluminense, um debate sobre o filme "O menino que descobriu o vento" escrito por William Kamkwamba e Bryan Mealer. Um dos pontos questionados sobre o filme foi a dificuldade de acesso a alimentos pela população mais pobre durante período de crises resultado do estoque de produtos e consequente aumento no preço de venda. Realizou-se um paralelo sobre esse assunto, a pandemia e aumento do preço de produtos essenciais durante a mesma, como o arroz que teve um aumento de $76,01 \%$ só durante 0 ano de 2020, segundo o IBGE. A partir do debate e das indagações iniciou-se o desenvolvimento de trabalhos em grupos durante os dois semestres letivos de 2020, visando promover a pesquisa científica, o pensamento crítico, o uso de softwares de modelagem $3 D$, a pesquisa por mecanização de processos de produção e a fabricação de protótipos com materiais que os alunos já possuíam em casa (evitando circular durante o isolamento social) para difundir propostas de inovação na mecanização dos processos de produção de arroz.

Palavras-chave: Ensino Remoto, Projeto, Metodologia Científica 


\section{ENSINO POR PROJETO: UMA ABORDAGEM DINÂMICA E LÚDICA EM TEMPOS DE ENSINO REMOTO}

\section{INTRODUÇÃO}

A pandemia do novo coronavírus gerou a necessidade de adaptar a educação as novas tecnologias, explicitando as diferentes realidades em que os alunos vivem e eclodindo na resistência nas escolas e universidades pelo país em iniciar o ensino remoto. Por outro lado, foi possível observar grupos que fizeram compras excessivas de insumos para estoque no início do isolamento social no Brasil, com a preocupação de uma possível falta de distribuição dos supermercados, evidenciando as disparidades de renda e necessidades alimentares em um mesmo país e o aumento da pobreza (CNN, 2021).

Objetivando trazer reflexão sobre questões sociais e financeiras vivenciadas no contexto atual, foi proposto aos alunos de Introdução à Engenharia Mecânica, disciplina do primeiro período da grade do curso de Engenharia Mecânica da Universidade Federal Fluminense, um debate sobre o filme "O menino que descobriu o vento" escrito por William Kamkwamba e Bryan Mealer.

O filme conta a história de William Kamkwanba e sua família (COMONERS, 2021), moradores de uma vila no Malawi onde a comunidade sobrevivia com 200 dólares anuais por pessoa e com a falta de itens básicos. William buscou estudar com a ajuda dos seus pais, apesar da falta de recursos. Muito interessado em estudar os princípios da eletricidade, ele descobriu a possibilidade de gerar energia através do vento e criou moinhos com a sucata da comunidade e restos de fiação que buscou em diferentes depósitos de lixos a céu aberto com ajuda de dois amigos, conseguindo fornecer energia e água para irrigar as plantações da comunidade.

O promovido debate acerca do filme durante o período remoto ressaltou pontos como a luta dos costumes antigos contra a modernização - assim como se percebe a dificuldade em ter um ensino remoto de qualidade e eficaz a toda população brasileira -, a importância da educação de qualidade para todos - assunto que ganhou visibilidade na discussão sobre o retorno das aulas em instituições públicas e privadas durante a quarentena no Brasil (IFSUL, 2020) - e a dificuldade em vislumbrar, através da inovação, a oportunidade para a solução de problemas e melhoria de processos - como, no filme, o pai de William não conseguia aceitar que o moinho projetado pelo filho salvaria a comunidade da seca e da fome.

Outro ponto fortemente questionado sobre "O menino que descobriu o vento" referese à dificuldade de acesso a alimentos pela população mais pobre durante período de crises resultado do estoque de produtos e consequente aumento no preço de venda. Neste contexto foi feito um paralelo sobre o assunto: com a pandemia e aumento do preço de produtos essenciais durante a mesma, como o arroz que teve um aumento de $76,01 \%$ (IBGE, 2020) só durante o ano de 2020.

A partir do debate e das indagações iniciou-se o desenvolvimento de trabalhos em grupos durante os dois semestres letivos de 2020, visando promover a pesquisa científica, o pensamento crítico, o uso de software de modelagem 3D, a pesquisa por mecanização de processos de produção e a fabricação de protótipos com materiais que os alunos já possuíam em casa (evitando circular durante o isolamento social), para difundir propostas de inovação na mecanização dos processos de produção de arroz. 


\section{METODOLOGIA}

A fim de estimular o networking entre os alunos que acabaram de iniciar a graduação e aumentar a interação em tempos de ensino remoto, os discentes foram separados em grupos entre 4 e 6 pessoas com temas diferentes sobre os processos de produção de arroz, conforme pode ser visto nas figuras abaixo (Figuras 1 e 2) - os sobrenomes dos alunos foram ocultados para garantir a privacidade dos mesmos.

Figura 1: Separação dos grupos no primeiro semestre letivo de 2020

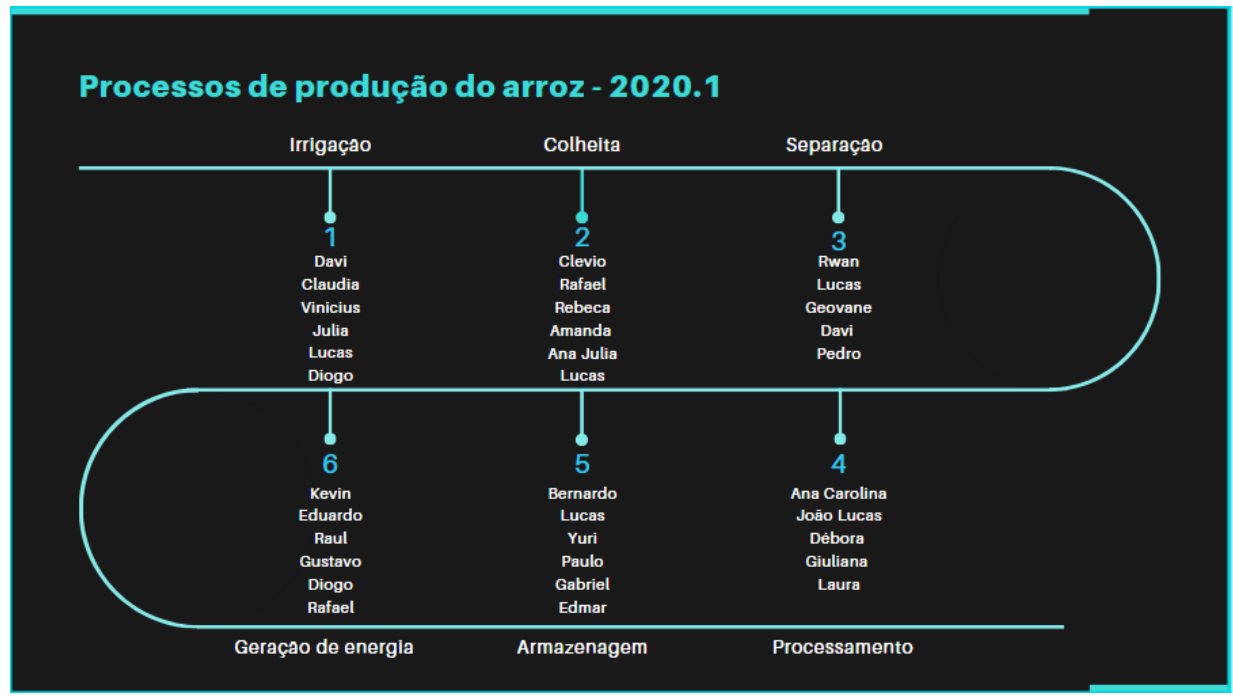

Fonte: Autoria própria

Figura 2: Separação dos grupos no segundo semestre letivo de 2020

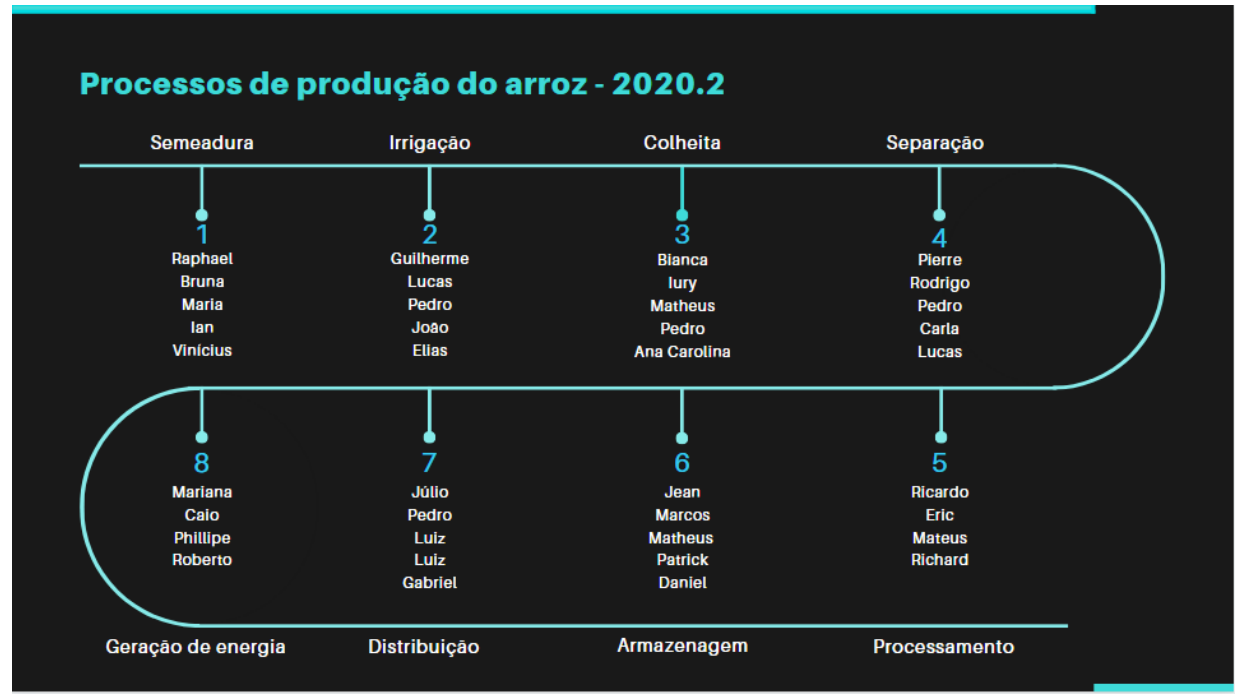

Fonte: Autoria própria

Sendo as etapas divididas:

a) Semeadura: refere-se à preparação do solo, adubação e lançamento de sementes no solo 
b) Irrigação: uso de água para saturar o mesmo após o processo de semeadura do mesmo

c) Colheita: recolhimento do produto fruto das etapas anteriores

d) Separação: divisão do produto em subprodutos ou para eliminação

e) Processamento: atividades necessárias para o arroz ser ensacado (limpar, secar, descascar, entre outros).

f) Armazenagem: pesagem, ensacamento e armazenagem do produto antes de ser distribuído

g) Distribuição: toda logística desde a semeadura até o produto final chegar aos clientes e consumidores

h) Geração de energia: possibilidades de geração de energia de forma não convencional para fazer todo o processo de produção de arroz funcionar

Os alunos receberam também um cronograma com datas e especificações de atividades que deveriam ser entregues parcialmente (Tabela 1). Algumas dessas práticas tiveram auxílio de capacitação dada previamente aos alunos, ajudando no aprendizado de conteúdos fora da grade curricular obrigatória do curso, mas que possui uma gama de funcionalidade e aplicações, como a modelagem em software 3D e o uso da abordagem do Design Thinking como ferramenta da inovação em projetos (UDESC, 2015)

Tabela 1: Cronograma para as turmas dos dois semestres letivos de 2020.

Data

$2020.130 / 10 / 2020$

2020.2 02/04/2021

$2020.113 / 11 / 2020$ 2020.2 09/04/2021

$2020.120 / 11 / 2020$ 2020.2 23/04/2021

$2020.127 / 11 / 2020$ 2020.2 30/04/2021

$2020.104 / 12 / 2020$ 2020.2 05/05/2021

$2020.109 / 12 / 2020$ 2020.2 07/05/2021
Entrega

Descrever sobre o tema destinado ao grupo

Escolher uma etapa dentro do tema destinado ao grupo, projetar uma mecanizada de forma inovadora e escrever a motivação para essa escolha

Desenhar o equipamento mecanizado (podendo ser feito à mão ou por modelagem)

Prototipar o equipamento da fase anterior, usando materiais que já tenham em casa

Aula para tirar dúvidas sobre a apresentação e entrega final da parte escrita Entrega do trabalho (apresentação de até 10 minutos e parte escrita em formato de artigo acadêmico)
Obs

$$
\begin{aligned}
& \text { Estimulação da } \\
& \text { pesquisa científica }
\end{aligned}
$$

Capacitação de Design Thinking. Indução de inovação em projetos e a pesquisa por mecanização nas operações
Capacitação do software Fusion $360^{\mathrm{TM}}$

Capacitação de Design

Thinking. Indução de inovação em projetos e análise de materiais

Fonte: Autoria própria

Prévia de apresentação e encorajamento da escrita científica 


\section{RESULTADOS}

Apesar da dificuldade inicial em idealizar e produzir um protótipo de forma remota, os grupos apresentaram soluções e prototipagens inovadoras para o trabalho proposto. É possível destacar algumas modelagens e protótipos entre todos os quatorze realizados durante o ano letivo de 2020.

Um dos grupos responsáveis em pesquisar sobre o processo de irrigação da produção do arroz apresentou uma inovação no sistema de turbina de distribuição de água, juntamente com uma técnica muito utilizada na Ásia - o uso de peixes para obtenção de nutrientes provenientes ao interagir com a água do arroz, ajudando na regulação do clima dentro do arrozal, obtenção de um solo mais macio, eliminação de larvas e ervas daninhas e atuação como fertilizante natural. Essa água que passou pelos peixes, girará a turbina em um eixo de rotação e um equipamento acima da turbina captará a água com os nutrientes - sendo auxiliado por uma roldana movida a energia potencial proveniente da turbina e do eixo de rotação do nível inferior -, que por sua vez leva a água para o seu destino final: o centro de distribuição através de encanamentos. Nas figuras 3 e 4 é possível observar a modelagem feita pelo software SketchUp® e prototipagem do projeto feito de peças Lego®.

Figura 3: Modelagem de um sistema de irrigação do processo de produção do arroz através do software SketchUp®

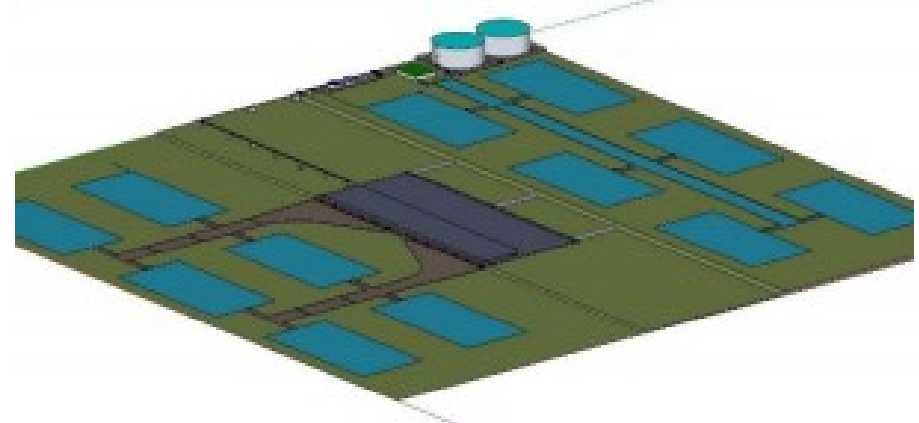

Fonte: autoria dos alunos

Figura 4: Protótipo feito de peças Lego®

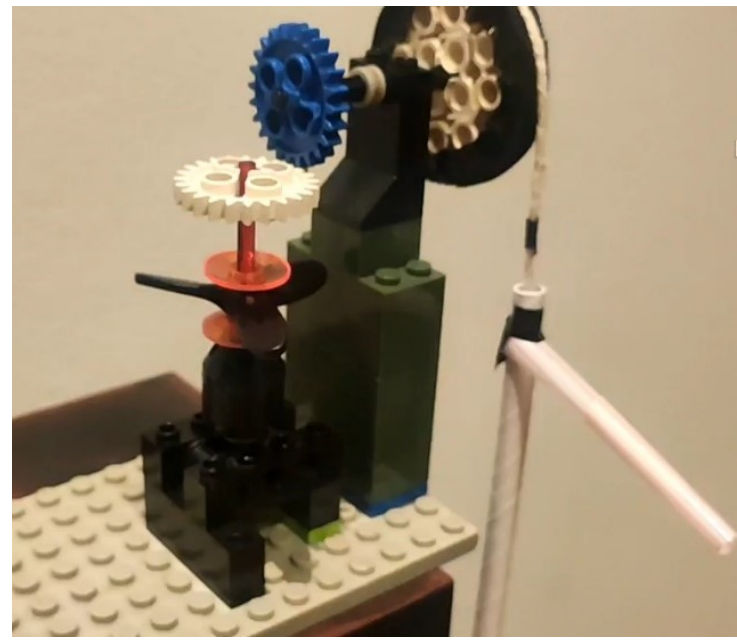

Fonte: autoria dos alunos 
Dentro do tema colheita no processo de produção de arroz a proposta de mecanização foi tornar o processo de corte automatizado, ou seja, adaptar o maquinário atual para que ele realize o corte e trilhamento do arroz de forma automática, sem interferência direta do operador. Para isso, é necessário a disposição de um sensor responsável pela identificação da direção do corte. A automação teria como benefício principal o corte de gastos, já que haverá capacidade de operação sem interrupções (sendo limitado apenas por combustível ou por uma possível falha mecânica), além de permitir que o operador se preocupe com a coleta e armazenagem dos grãos ao passo que o corte e trilhamento ocorrem, descartando a necessidade de mais trabalhadores para o processo. O grupo modelou a proposta pelo software Fusion $360^{\mathrm{TM}}$, prototipou usando palitos de picolé e uma programação básica no arduino (Figuras 5 e 6).

Figura 5: Modelagem de uma ceifadora de arroz automática no software Fusion 360
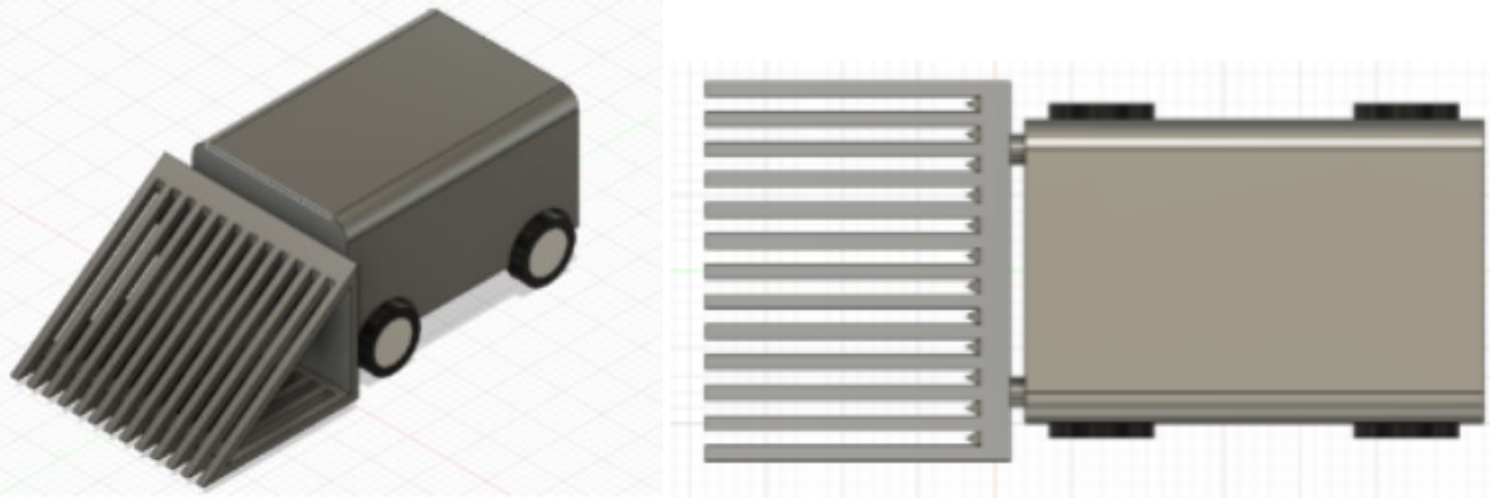

Fonte: autoria dos alunos

Figura 6: Protótipo de uma ceifadora de arroz automática

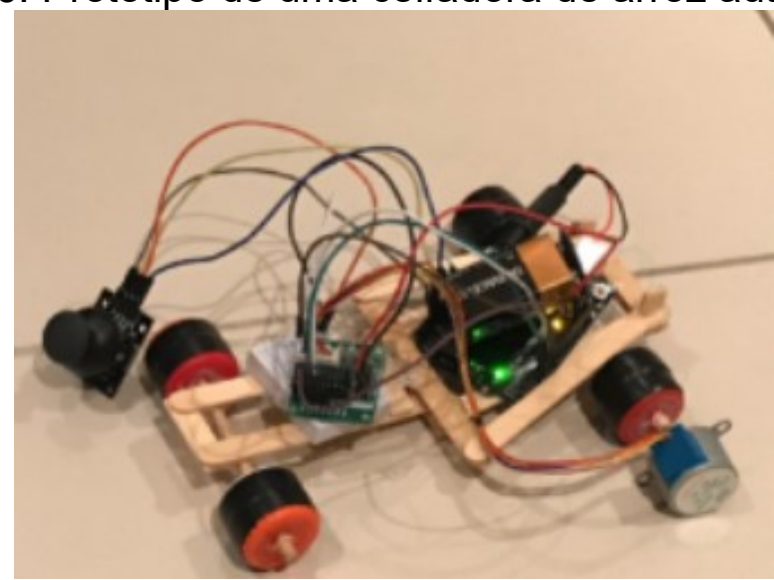

Fonte: autoria dos alunos

Por último é possível mencionar a sugestão de inovação de fabricar um braço mecânico para fazer os sacos de arroz e reposicionamento nas caixas para serem distribuídos. A mecanização dessa operação agiliza o processo de empacotamento final do produto e diminui o impacto negativo na saúde dos trabalhadores, já que esse processo é feito hoje de forma manual, ocasionando lesões corporais e exaustão aos responsáveis pela atividade. A modelagem foi feita no software SolidWorks $®$ e para prototipagem foram usados tubos de policloreto de vinila - tubos de PVC - (Figuras 7 e 8) 
Figura 7: Modelagem de um braço mecânico

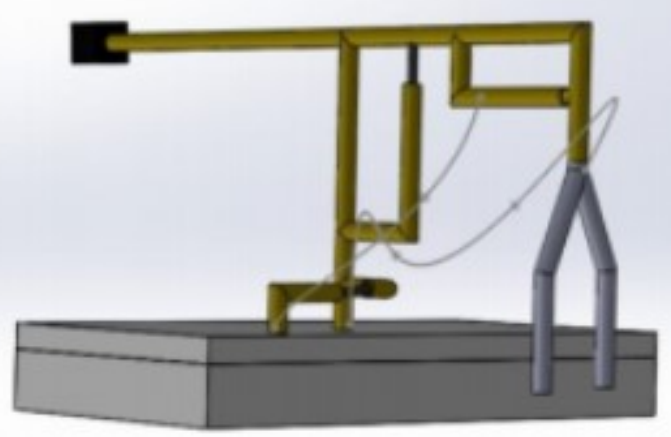

Fonte: autoria dos alunos

Figura 8: Protótipo de um braço mecânico

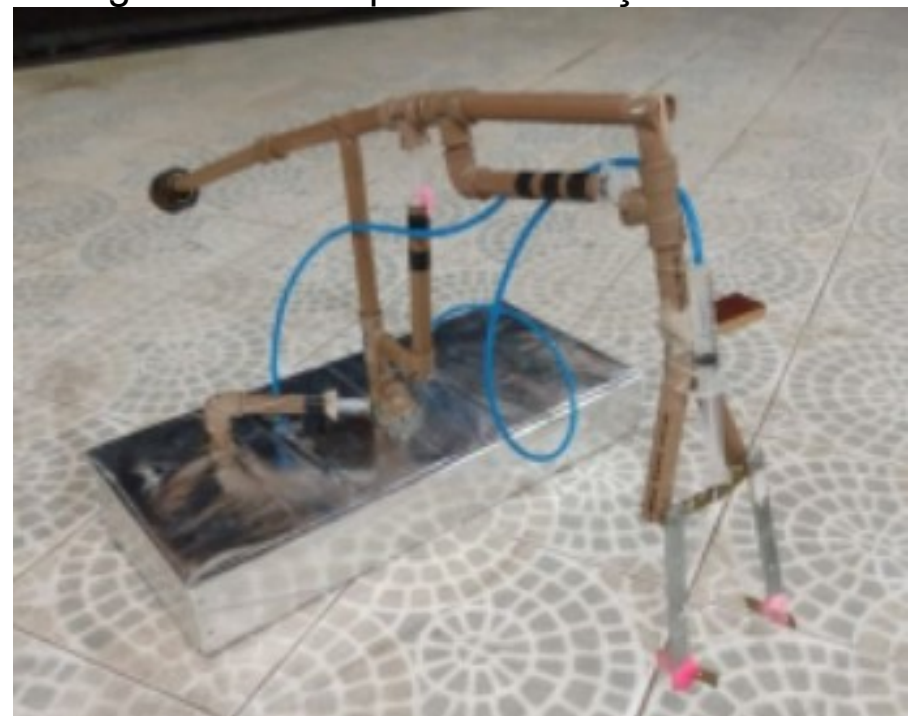

Fonte: autoria dos alunos

Todos os discentes demonstraram grande motivação para realizar a proposta apresentada, assim como a pesquisa científica feita sobre o processo de produção do arroz. Os alunos também se mostraram motivados para continuar a graduação de forma remota, além de relatarem como o trabalho incitou a inovação e o networking durante o semestre, como mostra alguns dos relatos disponibilizados na Tabela 2. 
Tabela 2: relatos de experiência dos alunos sobre a realização do trabalho

"O nosso trabalho foi no processo de armazenagem, isso nos levou a conhecer e entender as dificuldades enfrentadas pelo setor, o qual nos abriu um leque de ideias, que pudessem vir a ser realizadas a fim de inovar e corrigir certos problemas. Foi um trabalho em equipe, onde todos puderam evoluir. Foi interessante desde o processo de pesquisa a execução do trabalho final. Entendo que eu precise lapidar alguns pontos ao longo do curso, por isso ainda não me sinto completamente confiante em escrever um artigo científico sozinho. Porém me sinto apto o suficiente para fazer parte de um projeto de pesquisa em iniciação científica. Não necessariamente com a parte da escrita em si."

"Particularmente a parte a qual tive maior interesse e consequentemente a melhor relação foi na da criação de uma inovação de algo presente no processo e a confecção de seu mockup."

“O trabalho foi muito especial para mim, pois só a favor das energias renovávais já que eles não agridem o meio ambiente e são sustentáveis e apesar disso eu não sabia da utilização da casca do arroz para tal demanda logo foi um aprendizado em várias áreas."

"Gostei muito desse trabalho, pois além dele envolver o processo criativo também tinha um conhecimento teórico atrelado."

"Achei super envolvente e o grupo desenvolveu ótimas ideias a respeito"

Fonte: Autoria própria

\section{CONCLUSÃo}

Tendo em vista os resultados dos trabalhos e os relatos dos discentes da disciplina de Introdução à Engenharia Mecânica, é possível afirmar que a proposta apresentada impactou positivamente a experiência dos alunos com o primeiro período da graduação. Alguns alunos mencionaram se sentirem aptos para escrever um artigo científico já no primeiro período de graduação, tendo em vista que durante o desenvolvimento do projeto foram apresentados conceitos relacionados a metodologia científica, enquanto outros motivaram-se para fazer parte de alguma outra atividade extracurricular.

Observa-se que as capacitações ministradas em paralelo às aulas do período auxiliaram na confecção do trabalho (em $71 \%$ dos trabalhos foram apresentados desenhos modelados em algum software de modelagem 3D, conhecimento que não é lecionado em nenhuma disciplina da grade curricular obrigatória de Engenharia Mecânica na Universidade Federal Fluminense).

Dessa forma é perceptível que a atividade atingiu ao objetivo de criar networking entre os alunos num período de ensino remoto e fomentar a criatividade e a inovação deles. Também foi possível desenvolver competências como trabalho em grupo, comunicação, oratória, pensamento crítico, análise de materiais para a fabricação do protótipo, entre outros. Deste modo, a metodologia de ensino por projeto, inspirada em situações reais, torna-se uma alternativa promissora no que tange à introdução de conceitos e ferramentas importantes para formação acadêmica em Engenharia, sendo, portanto, uma forma dinâmica e lúdica de apropriação do conhecimento. 


\section{Agradecimentos}

Aos discentes calouros de Engenharia Mecânica da Universidade Federal Fluminense que cursaram a disciplina de Introdução à Engenharia Mecânica no ano letivo de 2020, pelo desempenho e entrega de trabalhos com excelente qualidade.

\section{REFERÊNCIAS}

BRAVO, Paula. Pandemia de Covid-19 causa pobreza sem precedentes na América
Latina.
CNN
Brasil.
Disponível
em:

<https://www.cnnbrasil.com.br/internacional/2021/03/05/pandemia-de-covid-19-causa-

pobreza-sem-precedentes-na-america-latina>. Acesso em: 28 de Abril de 2021.

COMONERS, O menino que descobriu o vento - crítica. Disponível em https://cosmonerd.com.br/filmes/critica/o-menino-que-descobriu-o-vento/ DEBORD, (2000) A sociedade do espetáculo. Acesso em: 30 de Abril de 2021

FUSION 360 ${ }^{\mathrm{TM}}, 2021$, Autodesk ${ }^{\circledR}$.

Índice Nacional de Preços ao Consumidor Amplo - IPCA | IBGE. Ibge.gov.br. Disponível em: $\quad<$ https://www.ibge.gov.br/estatisticas/economicas/precos-e-custos/9256-indicenacional-de-precos-ao--consumidor-amplo.html?=\&t=destaques $>$. Acesso em: 01 de Maio de 2021.

\section{LEGO® Brasil, 2021, Grupo LEGO®}

SKETCHUP®, 2020, Trimble Inc.

SCHNEIDER, Sergio; CASSOL, Abel; LEONARDI, Alex; et al. Os efeitos da pandemia da Covid-19 sobre o agronegócio e a alimentação. Estudos Avançados, v. 34, n. 100, p. 167188, 2020. Disponível em: <https://www.scielo.br/pdf/ea/v34n100/1806-9592-ea-34-100167.pdf>. Acesso em: 07 de Maio de 2021.

SOLIDWORKS®, 2002 - 2021, Dassault Systèmes SolidWorks Corporation

Vista do Design thinking como ferramenta para geração de inovação: um estudo de caso da Biblioteca Universitária da UDESC. Revistas.usp.br. Disponível em: <https://www.revistas.usp.br/incid/article/view/100887/103945>. Acesso em: 28 de Abril de 2021.

Vista do Percepções de estudantes do Ensino Médio das redes pública e privada sobre atividades remotas ofertadas em tempos de pandemia do coronavírus. Ifsul.edu.br.

Disponível

em:

<http://periodicosnovo.ifsul.edu.br/index.php/thema/article/view/1837/1542>. Acesso em: 07 de Maio de 2021. 


\title{
TÍTULO EM INGLÊS
}

\begin{abstract}
The Covid-19 pandemic generated the need to adapt education to new technologies, explaining the different realities in which students live and breaking out in resistance in schools and universities across the country to start remote education. On the other hand, it was possible to observe groups that made excessive purchases of inputs for stock at the beginning of social isolation in Brazil, with the concern of a possible lack of distribution in supermarkets, showing disparities in income and the increase in poverty. Wanting to bring reflection on social and financial issues experienced in the current context, it was proposed to students of Introdução à Engenharia Mecânica, discipline of the first period of the Mechanical Engineering course at Universidade Federal Fluminense, a debate about the film "The Boy Who Harnessed the Wind" written by William Kamkwamba and Bryan Mealer. One of the questions raised about the film refers to the difficulty of access to food by the poorest population during a period of crisis, as a result of the stock of products and the consequent increase in the sale price. A parallel was made on this subject, the pandemic and the increase in the price of essential products during the same, such as rice, which had an increase of $76.01 \%$ only during the year 2020. From the debate and inquiries, the development of group work began during of 2020, aiming to promote scientific research, critical thinking, the use of $3 D$ modeling software, research by mechanization of production processes. and the manufacture of prototypes with materials that the students already had at home (avoiding circulating during social isolation) to disseminate proposals for innovation in the mechanization of rice production processes.
\end{abstract}

Keywords: Innovation, Mechanical Engineering, Mechanization of Rice Production Processes, Prototype, Remote Education 